\title{
Profile of vision function amongst learners with low vision attending inclusive schools in Kakamega County, Kenya
}

\begin{tabular}{|c|c|}
\hline \multicolumn{2}{|c|}{$\begin{array}{l}\text { Authors: } \\
\text { Doreen E. Ashioya } 10 \\
\text { Peter C. Clarke-Farr }\end{array}$} \\
\hline \multicolumn{2}{|c|}{$\begin{array}{l}\text { Affiliations: } \\
{ }^{1} \text { Department of Optometry } \\
\text { and Vision Science, School } \\
\text { of Public Health, Biomedical } \\
\text { Science and Technology, } \\
\text { Masinde Muliro University } \\
\text { of Science and Technology, } \\
\text { Kakamega, Kenya }\end{array}$} \\
\hline \multicolumn{2}{|c|}{$\begin{array}{l}{ }^{2} \text { Department of Ophthalmic } \\
\text { Sciences, Faculty of Health } \\
\text { and Wellness Sciences, Cape } \\
\text { Peninsula University of } \\
\text { Technology, Cape Town, } \\
\text { South Africa }\end{array}$} \\
\hline \multicolumn{2}{|c|}{$\begin{array}{l}\text { Corresponding author: } \\
\text { Doreen Ashioya, } \\
\text { dashioya@mmust.ac.ke }\end{array}$} \\
\hline \multicolumn{2}{|c|}{$\begin{array}{l}\text { Received: } 10 \text { Aug. } 2020 \\
\text { Accepted: } 10 \text { Feb. } 2021 \\
\text { Published: } 29 \text { Apr. } 2021\end{array}$} \\
\hline \multicolumn{2}{|c|}{$\begin{array}{l}\text { How to cite this article: } \\
\text { Ashioya DE, Clarke-Farr PC. } \\
\text { Profile of vision function } \\
\text { amongst learners with low } \\
\text { vision attending inclusive } \\
\text { schools in Kakamega County, } \\
\text { Kenya. Afr Vision Eye Health. } \\
\text { 2021;80(1), a605. https://doi. } \\
\text { org/10.4102/aveh.v80i1.605 }\end{array}$} \\
\hline \multicolumn{2}{|c|}{$\begin{array}{l}\text { Copyright: } \\
\text { (c) 2021. The Author(s). } \\
\text { Licensee: AOSIS. This work } \\
\text { is licensed under the } \\
\text { Creative Commons } \\
\text { Attribution License. }\end{array}$} \\
\hline \multicolumn{2}{|l|}{ Read online: } \\
\hline 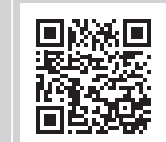 & $\begin{array}{l}\text { Scan this QR } \\
\text { code with your } \\
\text { smart phone or } \\
\text { mobile device } \\
\text { to read online. }\end{array}$ \\
\hline
\end{tabular}

Background: The quality of vision function of low vision (LV) children determines their ease and success in performing activities of daily living including academic activities undertaken whilst at school.

Aim: The aim of this study was to determine the vision function of LV learners attending inclusive schools in Kakamega County, Kenya.

Setting: This study was designed at public primary inclusive schools in Kakamega County, with LV placements by the County Educational Assessment and Resource Center.

Methods: This was a school-based cross-sectional study. A census survey identified 21 LV learners, who met the World Health Organization (WHO) classification of LV and had been assessed and placed in 11 public primary inclusive schools in Kakamega County. Participants underwent standard LV assessment tests. Data were entered into Statistical Package for the Social Sciences (SPSS) version 25 software and analysed using descriptive and inferential statistics. Data were summarised and presented using tables, figures and percentages.

Results: Out of the $21 \mathrm{LV}$ learners who were selected, 19 (90.5\%) were assessed. The best recorded visual acuity (VA) was 0.33 decimal notation at far and 0.02 and 0.01 in the right eye and the left eye, respectively, at near. The vast majority, $94.7 \%$, had reduction in stereopsis, whilst $42.1 \%$ had defects in colour vision, $20.0 \%$ reduced contrast sensitivity (CS) and $15.8 \%$ had visual field impairment within the central 20 degrees.

Conclusion: There is an overall decrease in vision function amongst LV learners attending inclusive schools in Kakamega County. The most affected parts of vision function are VA and stereopsis.

Keywords: visual function; low vision; visual acuity; contrast sensitivity; stereopsis; colour vision; visual field.

\section{Introduction}

Approximately 36 million people suffer from blindness whilst 216.6 million are visually impaired worldwide. ${ }^{1}$ In Africa, the prevalence of moderate to severe visual impairment was estimated to be 16.8 million in the year 2010 and was higher in females than males. ${ }^{2}$ Vision loss is caused by a number of factors, including age, glaucoma, cataracts and age-related macular degeneration (AMD). ${ }^{3}$ The burden of visual impairment is high in developing countries and considerably higher in children $(42.14 \%){ }^{4}$ Most of the causes of visual impairment amongst school-aged children are avoidable. ${ }^{5}$

Low vision (LV) forms part of visual impairment and is defined as patients who have a visual acuity (VA) of less than 6/18 to 3/60 in the better eye or a visual field of less than 10 degrees from the point of fixation after best correction with spectacles or medication. ${ }^{6}$ Low vision has a negative impact not only on the lives of the visually impaired people but also on their family and society at large. Furthermore, studies have shown that LV lowers the quality of life of the affected patients. ${ }^{7}$

Vision function comprises of five aspects: VA, visual field, colour vision, contrast sensitivity (CS) and stereopsis. ${ }^{8}$ These aspects of vision determine the ability of an individual to engage in tasks and activities of daily living. The visual ability must be measured against the value 
of independent living of LV patients, ${ }^{9}$ and VA is defined as the resolving power of the eye. Better results on VA measurement are obtained on the Early Treatment Diabetic Retinopathy Study (ETDRS) chart as compared with the Snellen's chart especially with decreasing vision. ${ }^{10}$ The distance and near LogMAR charts show high repeatability on high contrast for letters presented both horizontally and vertically. ${ }^{11}$ This therefore makes the LogMAR chart most suitable for assessing VA because VA is assessed at $100 \%$ contrast. However, variability between the distance and near VA increases with decreasing contrast. Some of the leading causes of decrease in VA in children in Malawi were amblyopia and refractive errors. ${ }^{12}$ Children with better VA express better motor skills than LV children. ${ }^{13}$

Another important aspect of visual function is CS. Defective CS is seen in many cases of cortical visual impairment, which is the leading cause of visual impairment amongst children in the western countries. ${ }^{14}$ Contrast sensitivity is expected to mature to adult threshold between the age of 8 and 13 years. ${ }^{15}$ Many paediatric conditions such as congenital glaucoma, myopia and optic pathway gliomas can affect CS despite normal VA. ${ }^{16}$ Despite all this, reliable assessment of paediatric CS is limited. ${ }^{16}$

Another aspect of vision function is colour vision, which affects approximately $8 \%$ of the male population. ${ }^{17}$ Colour vision defects occur when there is a mutation or rearrangement in the genes that encode the short, middle and long wavelengths of light. ${ }^{18}$ In southern California, colour vision deficiency amongst boys was $1.4 \%$ in black people and $3.1 \%$ in Asians, whilst the prevalence in girls was considerably lower at $0.0 \%-0.5 \%$ for all ethnicities. ${ }^{19}$ A study conducted amongst primary school going children in Ethiopia revealed that the prevalence of colour vision deficiency was $1.6 \%$ and was higher in boys than girls. ${ }^{20}$ Similarly, a study carried out in Iran reported that prevalence of colour vision deficiency was higher in males than females. ${ }^{21}$

Stereopsis, the ability to visualise objects in three dimensions, increases rapidly from the age of 4-7 years. ${ }^{22}$ Severe visual impairment in children worsens their stereo acuity more than mild visual impairment. ${ }^{23}$ In addition, good stereopsis is important for engaging in certain careers such as dentistry or other occupations where detection of fine changes in depth is needed. ${ }^{24}$ Stereopsis is significantly affected in children who are amblyopic and myopic. ${ }^{25}$ For the measurement of stereopsis, the Random Dot (Randot) Stereo Acuity Chart has been widely used to assess stereopsis in children aged from three years through into their teen years because of its high validity. ${ }^{26}$ The distance Randot stereo acuity test also shows high test-retest reliability when measuring binocular sensory function. ${ }^{27}$

Normal visual fields are another important aspect of visual function. Central vision is more stable and useful in scene recognition as compared with peripheral vision. ${ }^{28}$ Constrictions in visual field can be as a result of side effects of medication such as vigabatrin. ${ }^{29}$ Central visual loss leads to cortical thinning, whereas visual loss at the periphery leads to cortical thickening. ${ }^{30}$ Many LV patients who have central vision deficits are flexible enough to adjust to eccentric fixation after undergoing training. ${ }^{31}$ The visually impaired youths and adults have been proved to have reduced dynamic stability compared with their normal sighted peers. ${ }^{32}$ This highlights the great need to address the challenges encountered by LV learners by assessing their visual field and thereafter making proper interventions.

The inclusive learning system in the Kenyan context is a system of education in which physically impaired learners share the same classroom as other learners according to the Special Needs Education Policy. ${ }^{33}$ The government's aim of introducing an inclusive learning school system was to enable LV learners to get the classroom experience as their normal sighted peers. Full inclusion of an individual into mainstream schools is crucial because it enables them to participate in other function systems such as politics, science, economy and art. ${ }^{34}$ Implementation of inclusive school system in Kenya continues to face many challenges, which include inadequately trained teachers, inaccessibility to required training resources, increased demand for early intervention and assessment services. ${ }^{35,36}$ Whilst many factors were identified as hindering placement of disabled learners including visually impaired learners into mainstream schools, the visual performance aspect of it had been underexplored.

Although vision function affects academic performance, ${ }^{37}$ it is unclear how the visual functions of LV patients influence their participation in activities of daily living in inclusive schools. This is part of what informs their comfortability in the inclusive school's environment. Therefore, the assessment of these visual functions is a very important consideration to be made when learners with LV are being placed into the mainstream schools. The aim of this student was hence to determine the vision function of LV learners attending inclusive schools in Kakamega County, Kenya.

\section{Methods \\ Study design}

This study employed a school-based cross-sectional descriptive study design.

\section{Setting and study population}

The study was conducted in public primary inclusive schools, which host LV learners in Kakamega County, Kenya. Most LV learners attend special schools for the visually impaired and all the LV learners in inclusive schools in Kakamega County, aged 10-21 years, formed the study population for this research (VA of less than 6/18 in the better eye up to $3 / 60$ or a visual field of less than 10 degrees 
from the point of fixation after best correction). Out of the 76 inclusive schools in which visually impaired learners are hosted in Kakamega County, there are 11 schools in which typical LV learners are placed by the County Educational Assessment and Resource Center.

Learners with multiple disabilities were excluded from the study. This is because some disabilities such as autism affect the learners' cognitive reasoning and independent response and could affect how they respond to the Functional Vision Assessment Questionnaire. Low vision learners below 10 years were also excluded from this study because they would not be able to respond effectively to the questionnaire. Furthermore, learners whose parents did not give their assent or consent and learners with incompletely filled out questionnaires were excluded from this study.

\section{Data collection}

Prior to the collection of data, permission was sought from the heads of the schools in which the study was conducted. An informed consent form was administered to the LV learners who were above 18 years old prior to data collection. Similarly, guardians of learners who were below 18 years of age were given the same forms to sign on their behalf. Medical records of the participants were retrieved from the administration and used to elicit the diagnosis and VA of each participant at the time of admission. Data collection involved the procedures described as follows.

A chain of clinical tests relevant to visual function were conducted with the learners. The first test was assessment of VA at far point, which was conducted monocularly using Snellen's chart. Low vision learners were requested to read from the chart whilst standing $6 \mathrm{~m}$ away. The best VA for each eye was recorded. Visual acuity at near point was also recorded binocularly using the Near LogMAR chart. Participants were requested to read from the chart at a distance from $25 \mathrm{~cm}$ to $40 \mathrm{~cm}$. Their best vision attained was recorded in LogMAR values.

The second test was visual field assessment. This was conducted binocularly. It was important to assess the LV learners' visual field because this would enable the researcher to determine how much the field of view had constricted and hence deduce the likely effect on the learners' activities of daily living and their ability to read. Visual acuity was assessed for the central 20 degrees using the Amsler grid.

The third test was the assessment of colour vision using the Hardy-Rand Rittler (HRR) isochromatic plates chart. This test was carried out binocularly. This chart was most appropriate for testing colour vision because it enabled the examiner to assess learners who might suffer from both red-green and blue-yellow colour defects. Moreover, it would make it possible to classify the colour defect as mild, moderate or severe with HRR.

The fourth was the CS test, which was conducted binocularly using the $10 \mathrm{M}$ Lea symbol CS chart where the reciprocal of the lowest contrast threshold recorded would give the CS value. The chart was presented to the participants, who were expected to correctly identify the optotypes on each page as the contrast reduced gradually.

The fifth assessment was the stereopsis test conducted binocularly using the Random Dot stereo acuity test (Randot). The random dot test was conducted with learners wearing polarising lenses and reading symbols that are of different depths. The stereopsis test was key in this study because stereopsis plays a major role in task performance such as orientation and mobility. Low vision patients with poor stereo acuity are unable to clearly visualise objects in three dimensions. As a result, they are to prone to accidents when walking around.

Finally, there was an assessment of general ocular health to elicit any undiagnosed ocular condition that the learners may be having. This included anterior eye examination using a trans-illuminator and posterior eye examination using a direct ophthalmoscope. Learners who were diagnosed with any other ocular condition were referred to the academic vision centre at Masinde Muliro University for management. Those who needed surgery were referred to Sabatia Eye Hospital for review by an ophthalmologist.

\section{Data analysis}

The data collected in the research were entered into Microsoft Excel, edited, coded and thereafter the cleaned and verified data were transferred into the Statistical Package for the Social Sciences (SPSS) (version 25) software. Dependent and independent variables were derived, and data were analysed using descriptive statistics whilst values and percentages were presented using bar graphs and charts.

\section{Ethical considerations}

Ethical approval to conduct the research was obtained from the Institutional Review and Ethics Committee (IREC) of Masinde Muliro University of Science and Technology (MMUST/IERC/113/2020). Furthermore, a research permit was obtained from the National Commission of Science and Technology (NACOSTI) (Reference number: 523567). The researcher adhered to all the ethical protocols established by the institution and all data obtained and captured electronically were protected on a password-controlled computer so that only the researcher would have access to it. Data were stored as per the university archiving policy.

\section{Results}

\section{Distribution of low vision learners}

There were 12 male (68.4\%) and six female (31.6\%) LV learners, indicating an unequal gender distribution of LV 
learners attending Kakamega County inclusive schools. The age of the LV learners ranged from 10 to 21 years old. The highest number of learners was in the 13 year age group, whilst the mean age was 14.47 years with a standard deviation of 3.04 years. The results show a normal distribution curve across age where the least numbers were recorded at the tail ends of 10 and 21 years of age. The highest number of LV learners, six (31.6\%), were in Grade 8, whilst the lowest number recorded one each (5.3\%) were in Grades 1 and 2. All grades from 2 to 8 were represented in this study. More than half of the learners $(57.9 \%)$ were not sure of the duration for which they had been LV patients, whilst the rest of the learners $(42.1 \%)$ recorded a period of 5-16 years of visual impairment.

\section{Distance visual acuity of the right eye recorded in decimal notation}

The highest number of learners had a VA of $0.33(42.1 \%)$ recorded for the right eye, whilst the lowest had 0.01 (5.3\%). The VA for all the learners fell below the normal value of 1.0 decimal notation, which is equivalent to $6 / 6$ on the Snellen's chart. This shows that most of the learners had moderate vision loss in the right eye, whilst a few had severe impairment in their right eyes. Visual acuity was not the same in both eyes.

\section{Distance visual acuity of the left eye recorded in decimal notation}

Again, the highest number of learners had a VA of 0.33 (42.1\%) recorded for the left eye, whilst the lowest VA recorded was 0.02 in $10.5 \%$ of the learners. The lowest number of participants was with a VA of $0.1(5.3 \%)$. Similar to the right eye, the VA in the left eye showed moderate-to-severe impairment with all the values falling below the normal expected threshold (Figure 2).

\section{Near visual acuity recorded in LogMAR amongst learners}

The near VA values ranged from 0.05 LogMAR (highest) to 1.0 LogMAR (lowest). This implies that all the values were below the expected VA for normal sighted individuals, that is, 0.0 LogMAR. The highest percentage of learners had a VA of $0.06(15.8 \%)$, whilst the lowest percentage $(5.3 \%)$ was recorded against visual acuities of $0.05,0.1,0.13,0.32,0.4$ and 1.0 LogMAR. There was a fair distribution of learners across the different levels of visual impairment at near point.

\section{Contrast sensitivity recorded as an inverse of the contrast threshold (conducted binocularly)}

Almost half of the learners $(47.40 \%)$ had good CS scored at $80.00 \%$, whilst $31.60 \%$ scored $40.00 \%$, $5.30 \%$ scored $20.00 \%$, $5.30 \%$ scored $10.00 \%$ and $10.50 \%$ had the lowest CS score of $4.00 \%$. Findings of this study indicated that CS might not be a major concern for the LV learners in inclusive schools in Kakamega County because only very few were affected by significantly poor contrast.

\section{Stereopsis (conducted binocularly)}

More than a third $(36.8 \%)$ of learners had very poor stereopsis of $400 \mathrm{~s}$ of arc, whilst $15.8 \%$ had no stereopsis at all. The rest of the learners recorded $200 \mathrm{~s}$ of arc $(26.3 \%)$ and $100 \mathrm{~s}$ of arc (15.8\%). Only 5.3\% had normal stereopsis but all the rest had some form of stereopsis impairment. Values for normal stereopsis are 40 arcsec or less and only one learner scored within what is prescribed as normal stereopsis (Figure 5).

\section{Visual field using the Amsler grid (conducted binocularly)}

The majority of learners had normal central visual fields $(84.2 \%)$, whilst only $15.8 \%$ had scotomas in one or all the quadrants. Of the learners who presented with impaired central visual field, 5.3\% reported lower quadrant scotomas, $5.3 \%$ had scotomas in all quadrants and another $5.3 \%$ had missing lines along the diagonal line direction. Therefore, visual fields of LV learners attending inclusive schools in Kakamega County were mostly intact except for a few who had scotomas in one or several quadrants of their visual fields (Figure 6).

\section{Colour vision using the Hardy-Rand Rittler chart (conducted binocularly)}

More than half of the learners (57.9\%) had normal colour vision, but $36.8 \%$ had a mild red-green colour vision defect whilst one learner appeared to have both mild red-green and blue-yellow colour defect. Red-green colour defect was recorded as the most common colour vision defect amongst the LV learners in these inclusive schools whilst blue-yellow colour vision defect was less prevalent (Figure 7).

\section{Discussion}

\section{Demographics of low vision learners}

There were more male than female LV learners attending the inclusive schools in Kakamega County (Table 1). This is contrary to a study that was done in Asia, Africa and Latin America which showed that LV was higher in girls than in boys. ${ }^{38}$ There were also more LV learners in grade eight, the highest grade in Kenyan Primary school system, as compared with the lower grades. Studies have not identified the relationship between LV and grade or level of education. This could possibly be attributed to the challenges with inclusive learning in Kenya, which may have led to a decrease in the admission of LV learners into mainstream schools down the years. The majority of the LV learners were unaware of when they became visually impaired, but $42.1 \%$ indicated that they had been impaired for a period of between 5 and 16 years. This corresponds with the findings of a study by Khan et al. ${ }^{39}$ that identified lack of awareness as a barrier to the provision and uptake of LV services.

\section{Visual function of low vision learners}

The distance VA ranged between 0.33 and 0.01 (in decimal notation) for the right eye (Figure 1) and 0.33 and 0.02 for the 
TABLE 1: The demographics of children with low vision in inclusive schools.

\begin{tabular}{|c|c|c|}
\hline Variables & Number $(n)$ & $\%$ \\
\hline \multicolumn{3}{|l|}{ Gender } \\
\hline Male & 13 & 68.4 \\
\hline Female & 6 & 31.6 \\
\hline \multicolumn{3}{|l|}{ Age } \\
\hline 10 & 1 & 5.3 \\
\hline 11 & 2 & 10.5 \\
\hline 12 & 1 & 5.3 \\
\hline 13 & 6 & 31.6 \\
\hline 14 & 2 & 10.5 \\
\hline 15 & 1 & 5.3 \\
\hline 16 & 1 & 5.3 \\
\hline 18 & 3 & 15.8 \\
\hline 19 & 1 & 5.3 \\
\hline 21 & 1 & 5.3 \\
\hline \multicolumn{3}{|l|}{ Grade } \\
\hline 2 & 1 & 5.3 \\
\hline 3 & 1 & 5.3 \\
\hline 4 & 2 & 10.5 \\
\hline 5 & 3 & 15.8 \\
\hline 6 & 2 & 10.5 \\
\hline 7 & 4 & 21.1 \\
\hline 8 & 6 & 31.6 \\
\hline \multicolumn{3}{|c|}{$\begin{array}{l}\text { Duration of impairment } \\
\text { (years) }\end{array}$} \\
\hline 11 & 1 & 5.3 \\
\hline 13 & 2 & 10.5 \\
\hline 14 & 1 & 5.3 \\
\hline 15 & 1 & 5.3 \\
\hline 16 & 1 & 5.3 \\
\hline 5 & 1 & 5.3 \\
\hline 6 & 1 & 5.3 \\
\hline Not sure & 11 & 57.9 \\
\hline
\end{tabular}

left eye (Figure 2), whilst the near VA (both eyes) ranged from 0.05 LogMAR (highest) to 1.0 LogMAR (lowest) (Figure 3). The VA with the highest number of learners was 0.06. The expected value for normal VA in LogMAR is 0.0, which implies that the closer a value is to zero, the better the vision is. Whilst good vision performance is associated with good academic performance, ${ }^{37}$ it is clear that all the LV learners in Kakamega County had poor vision and this is likely to affect their academic performance at school. A study in Singapore conducted amongst children, however, established that distance VA does not affect the academic performance of children aged $9-10$ years ${ }^{40}$ but it is unclear whether impaired near vision would significantly affect academic performance.

The study found out that $47.4 \%$ of LV learners attending the inclusive school system in Kakamega County had normal CS, whilst only a few LV learners (21.2\%) exhibited some level of deficiency in CS; a value below $40 \%$ (Figure 4). This is comparable to the recent findings of Chung and Legge, ${ }^{41}$ a study which established that CS values in LV persons were comparable with those of normal sighted individuals. Contrast sensitivity is expected to have matured to adult-like performance between the ages of 8 and 19 years. ${ }^{15}$ This could be the reason why most of the learners in this study had normal CS because they were all above the minimum age

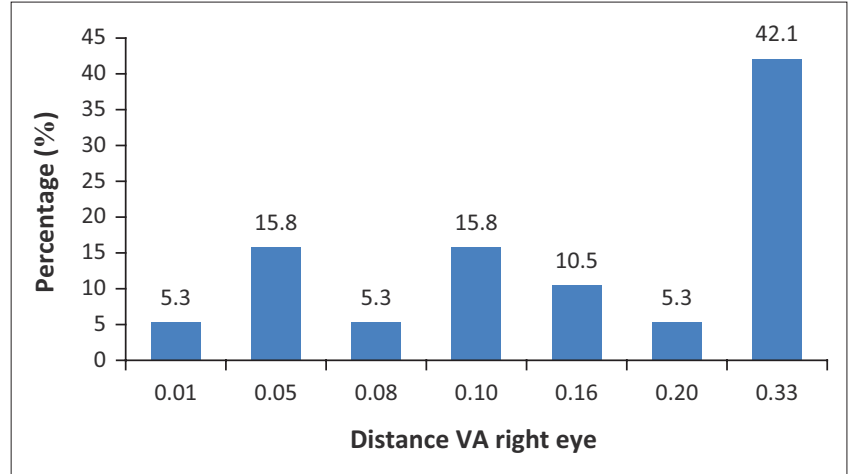

VA, visual acuity.

FIGURE 1: Distance visual acuity of the right eye recorded in decimal notation.

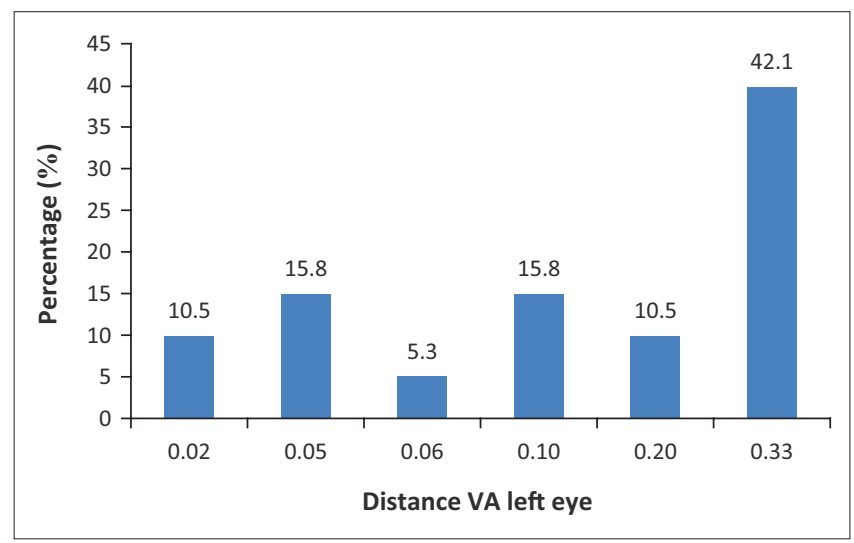

VA, visual acuity.

FIGURE 2: Distance visual acuity of the left eye recorded in decimal notation.

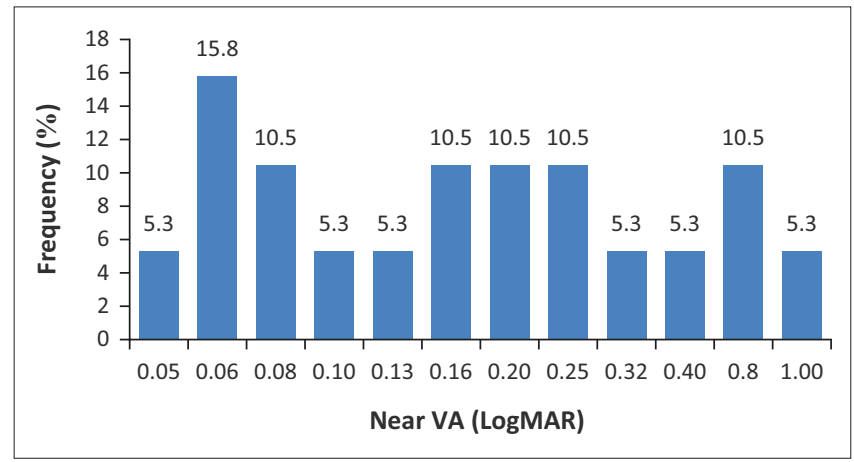

VA, visual acuity.

FIGURE 3: Near visual acuity recorded in LogMAR.

from which CS starts maturing to adulthood threshold. A few learners, however, still fell below the expected threshold.

Measurement of stereopsis revealed that only 5.3\% of LV learners in the inclusive schools have normal stereopsis of below $40 \mathrm{~s}$ of arc (Figure 5). In as much as stereopsis, unlike other aspects of visual function, varies from person to person, ${ }^{42}$ findings of this study clearly show that most learners fall way below the normal expected values of stereopsis. This shows that LV could be linked to poor stereopsis amongst the LV learners and is a major concern. Whilst there is a study whose findings indicate that the children with severe visual impairment demonstrate 


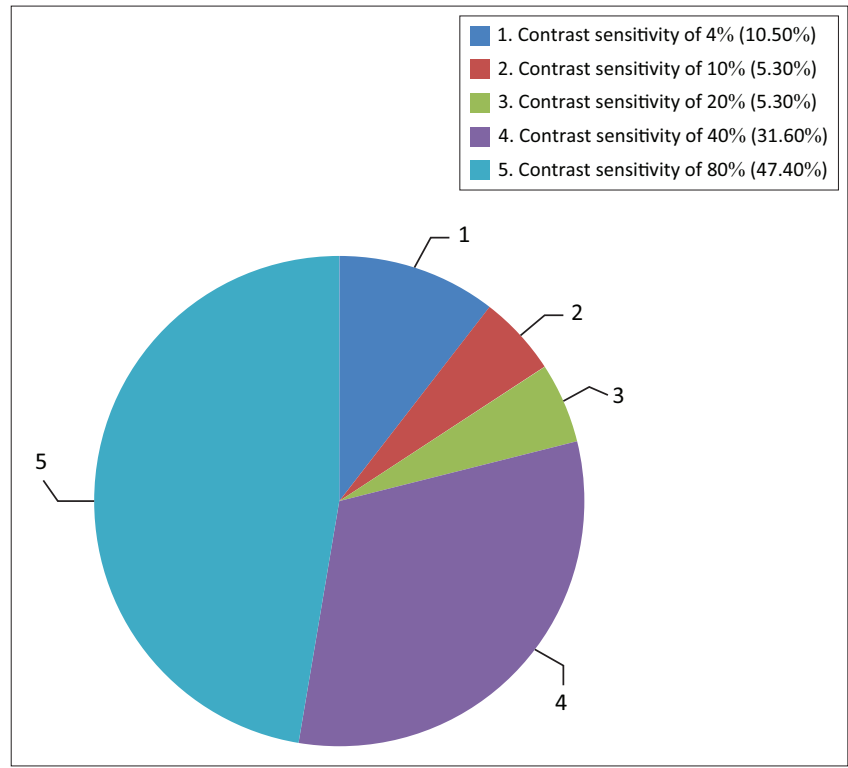

FIGURE 4: Contrast sensitivity recorded as an inverse of the contrast threshold.

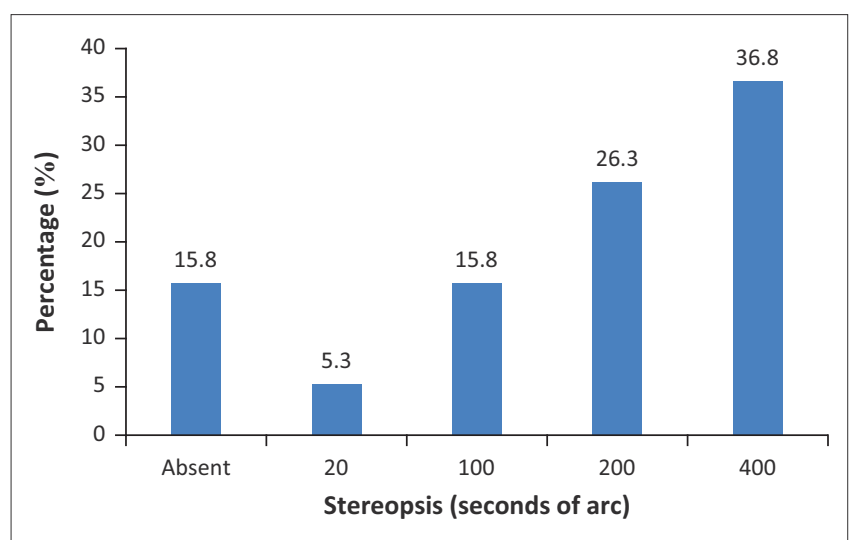

FIGURE 5: Stereopsis findings.

significantly lower stereopsis than those with milder visual impairment, ${ }^{43}$ this study reported a decrease in stereopsis more remarkably amongst learners with significant loss in one eye. This could be because stereopsis is a function of binocular vision, hence severe impairment of one eye deprives one from being able to exhibit the functions of binocular vision. Good stereopsis leads to good performance in motor skills. ${ }^{44}$ The poor stereopsis recorded amongst LV learners in this study is, therefore, likely to result in poor performance of activities of daily living and in the school environment.

The measurement of central visual fields revealed that the majority of the LV learners had normal visual fields (both eyes), whilst only a few had some form of scotomas in one or more quadrants (Figure 6). This could mean that central visual field loss is not amongst the aspects of visual function that are severely affected amongst LV learners. It may also be indicative of the types of ocular diseases that may cause VI in young people as opposed to older age who may have long established glaucoma or AMD. Furthermore, a previous study $^{31}$ showed that many LV patients who have central vision deficits are flexible enough to adjust to eccentric

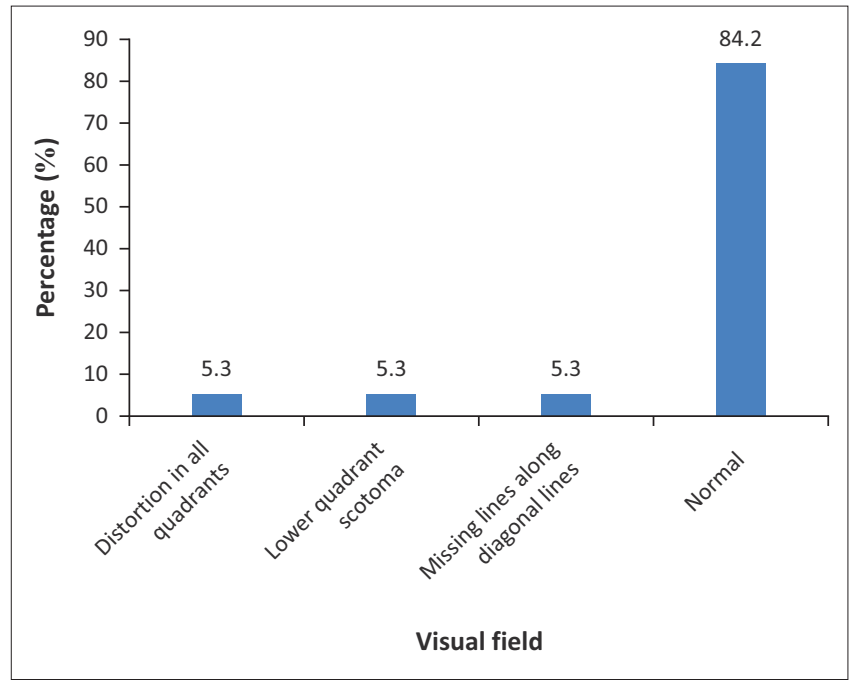

FIGURE 6: Visual field using the Amsler grid.

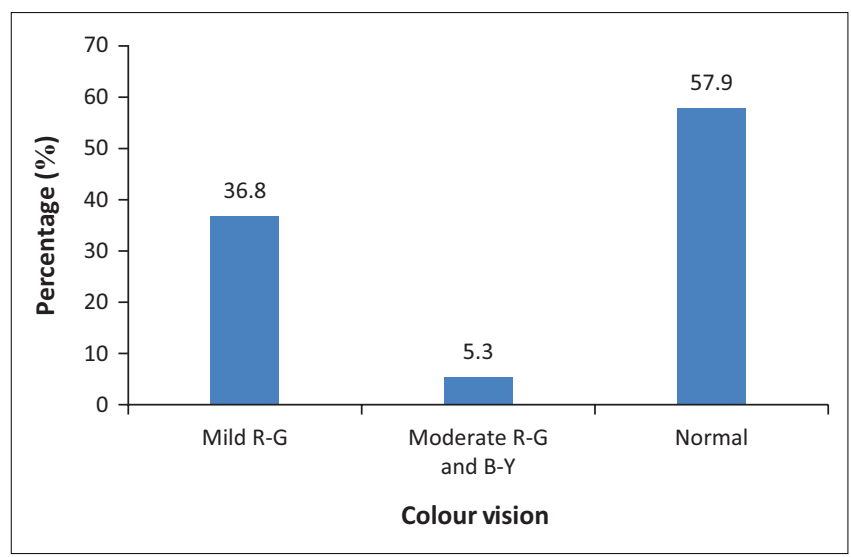

R-G, red-green; B-Y, blue-yellow.

FIGURE 7: Colour vision using the Hardy-Rand Rittler chart.

fixation after undergoing training. This could imply that even if central vision was affected, the learners would probably make use of eccentric fixation when performing tasks like reading. It is important, however, to address any deficit in central vision because central vision loss causes greater instability when a LV patient is presented with secondary tasks. ${ }^{45}$

The assessment of colour vision, conducted binocularly, revealed that $57.9 \%$ of LV learners in inclusive schools in Kakamega County had normal colour vision (Figure 7). Of the LV learners who had defective colour vision, there were more learners with red-green colour vision defect than blueyellow colour vision defect. This is similar to previous findings from a study by Graham et al., 1996, ${ }^{46}$ which showed that red-green colour vision defect is more prevalent than blue-yellow colour vision defect. This also supports the findings of a study by Rushton, which showed that most persons who have defective colour vision are still able to identify colour along the blue-yellow axis. ${ }^{47}$ Findings of this study in Kakamega County recorded a case of the same learner experiencing an apparent blue-yellow and red-green colour vision defect. This could be because of the fact that red-green defects majorly occur in diseases of the inner 
retina whilst blue-yellow defects are mainly seen in the outer retina and long standing pathologies of the inner retina may result in changes in the outer retina ${ }^{48}$ hence make it possible for an individual to exhibit both defects. The prevalence of colour vision appeared to be much higher amongst the LV children as compared with their normal sighted peers as reflected in a previous study conducted amongst normal sighted school children by Aprioku and Awoyesuku. ${ }^{49}$ As colour vision may be affected by diseases affecting the retinal receptors and visual pathways, it is therefore not unexpected that colour defects would be more common in those with LV caused by these conditions.

\section{Conclusion}

The findings of this study have revealed that there is an overall decrease in vision function amongst LV learners attending inclusive schools in Kakamega County. The most affected parts of vision function are VA and stereopsis where $94.7 \%$ of the LV learners had poor or no stereopsis at all. Issues concerning vision function of LV learners need to be addressed so that there may be an improvement in their ability to perform activities of daily living in an inclusive school environment. The researcher recommends that assessment of vision function should be conducted during placement of LV learners into the inclusive school system and thereafter on a regular basis in order to detect and address the visual challenges that these learners are likely to face as they progress with their academic development. This ought to be followed by provision of the necessary optical and non-optical devices and the specialised training in the use of these devices in order to improve performance of daily activities both academically and socially. The limiting factor in this study was that there were only a small number of LV learners attending inclusive schools in Kakamega County; most of the learners are preferably taken to special schools for the visually impaired.

\section{Acknowledgements}

The authors would like to acknowledge Masinde Muliro University of Science and Technology for the technical support offered in this research by providing data collection equipment and an enabling environment to conduct the research.

\section{Competing interests}

The authors declared that there are no personal or financial interests that may have influenced them to write this article.

\section{Authors' contributions}

P.C.C-F. participated in the supervision of the Master's degree research conducted by D.A. and the development of the manuscript. D.A. wrote the manuscript with editorial revisions and technical input and writing from P.C.C-F.

\section{Funding information}

This research received no funding from any agency.

\section{Data availability}

The data from this study are readily available for use by other researchers and stakeholders.

\section{Disclaimer}

The views and opinions expressed in this article are those of the authors and do not necessarily reflect the official policy or position of any affiliated agency of the authors.

\section{References}

1. Bourne RRA, Flaxman SR, Braithwaite $T$, et al. Articles magnitude, temporal trends, and projections of the global prevalence of blindness and distance and near vision impairment: A systematic review and meta-analysis. Lancet Glob Health. 2010;5(9):E888-E897. https://doi.org/10.1016/S2214-109X(17)30293-0

2. Naidoo K, Gichuhi S, Basáñez M, et al. Prevalence and causes of vision loss in subSaharan Africa: 1990-2010. Br J Ophthalmol. 2014;98:612-618. https://doi. org/10.1136/bjophthalmol-2013-304081

3. Cherinet FM, Tekalign SY, Anbesse DH, Bizuneh ZY. Prevalence and associated factors of low vision and blindness among patients attending St. Paul's Hospital Millennium Medical College, Addis Ababa, Ethiopia. BMC Ophthalmol. 2020;18:232. https://doi.org/10.1186/s12886-018-0899-7

4. Kinengyere P, Kizito S, Kiggundu JB, Ampaire A, Wabulembo G, Kizito S. Burden, etiology and predictors of visual impairment among children attending Mulago National Referral Hospital eye clinic, Uganda. Afr Health Sci. 2017;17(3):877-885. https://doi.org/10.4314/ahs.v17i3.31

5. Epkenyong BN, Ekanem E, Naidoo K, Ndep A, Akpan $M$. Prevalence and determinants of visual impairment amongst school-aged children in Southern Nigeria. Afr Vision Eye Health. 2020;79(1):1-6. https://doi.org/10.4102/aveh. v79i1.534

6. Resnikoff S, Pascolini D, Etya'ale D, et al. Policy and practice global data on visual impairment in the year 2002. Bull World Health Organ. 2004;82(11):844-851.

7. Gyawali R, Paudel N, Adhikari P. Quality of life in Nepalese patients with low vision and the impact of low vision services. J Optom. 2012;5(4):188-195. https://doi. org/10.1016/j.optom.2012.05.002

8. Braddick 0 , Atkinson J. Development of human visual function. Vision Res. 2011;51(13):1588-1609. https://doi.org/10.1016/j.visres.2011.02.018

9. Massof RW. A systems model for low vision rehabilitation II: Measurement of vision disabilities.Optom VisSci.1998;75(5):349-373.https://doi.org/10.1097/00006324199805000-00025

10. Kaiser PK. Prospective evaluation of visual acuity assessment: A comparison of snellen versus ETDRS charts in clinical practice (An AOS thesis). Trans Am Ophthalmol Soc [serial online]. 2009 [cited n.d.];107:311-324. Available from: https://pubmed.ncbi.nlm.nih.gov/20126505/

11. Cho P, Woo GC. Repeatability of the Waterloo four-contrast LogMAR visual acuity chart and near vision test card on a group of normal young adults. Ophthalmic Physio Opt. 2004;24(5):427-435. https://doi.org/10.1111/j.1475-1313.2004.00216.x

12. Thompson S, Naidoo K, Gonzalez-Alvarez C, Harris G, Chinanayi F, Loughman J. Barriers to use of refractive services in Mozambique. Optom Vis Sci. 2015;92(1) 59-69. https://doi.org/10.1097/OPX.0000000000000431

13. Uysal S, Düger T. [A comparison of motor skills in Turkish children with different visual acuity]. Fizyoter Rehabil. 2019;22(1):23-29. Turkish.

14. Good WV, Hou C, Norcia AM. Spatial contrast sensitivity vision loss in children with cortical visual impairment. Invest Ophthalmol Vis Sci. 2012;53:7730-7734. https://doi.org/10.1167/iovs.12-9775

15. Leat SJ, Yadav NK, Irving EL. Development of visual acuity and contrast sensitivity in children. J Optom. 2009;2(1):19-26. https://doi.org/10.3921/ joptom.2009.19

16. Milling $A F$, Hons $M$, Connor $A R O$, et al. The importance of contrast sensitivity testing in children. Br Ir Orthopt J. 2014;11:9-14. https://doi.org/10.22599/bioj.79

17. Jenny B, Kelso NV. Color design for the color vision impaired. Cartogr Perspect. 2007;58(2007):61-67. https://doi.org/10.14714/CP58.270

18. Neitz J, Neitz M. The genetics of normal and defective color vision. Vision Res. 2011;51(7):633-651. https://doi.org/10.1016/j.visres.2010.12.002

19. Xie JZ, Tarczy-Hornoch K, Lin J, et al. Color vision deficiency in preschool children. Ophthalmology. 2016;121(7):1469-1474. https://doi.org/10.1016/j. ophtha.2014.01.018

20. Geletu TT, Muthuswamy M, Raga TO. Identification of color blindness among selected primary school children in Hararghe region, eastern Ethiopia. Alexandria J Med. 2018;54(4):327-330. https://doi.org/10.1016/j.ajme.2018.07.001

21. Hashemi H, Khabazkhoob M, Pakzad R, Yekta A, Heravian J. The prevalence of color vision deficiency in the northeast of Iran. J Curr Ophthalmol. 2019;31(1): 80-85. https://doi.org/10.1016/j.joco.2017.05.005

22. Guo D, Wu J, Hu Y, Sun W, Lv T. Stereoacuity and related factors: The Shandon Children Eye Study. PLoS One. 2016:11(7);e0157829. https://doi.org/10.1371/ journal.pone.0157829 
23. Cole L, Kramer PR, Editors. Chapter 3.4 - Brain and nervous system. Human Physiology Biochemistry and Basic Medicine, Academic Press, 2016:93-99. https://doi.org/10.1016/B978-0-12-803699-0.00027-X

24. Syrimi M, Ali N. The role of stereopsis (three-dimensional vision) in dentistry: Review of the current literature. Br Dent J. 2015;218(10):597-598. https://doi. org/10.1038/sj.bdj.2015.387

25. Levi DM, Knill DC, Bavelier D. Stereopsis and amblyopia: A mini-review. Vis Res. 2020;(2012):17-30. https://doi.org/10.1016/j.visres.2015.01.002

26. Gharat A, Research $O$. A study of stereopsis in children and adolescents with myopic refractive error. Int J Contemp Med Res. 2015;4(1):2393-2915.

27. Matsuo T, Negayama R, Sakata H, Hasebe K. Correlation between depth perception by three-rods test and stereoacuity by distance randot stereotest. Strabismus. 2014;22(3):133-137. https://doi.org/10.3109/09273972.2014.939766

28. Thibaut M, Ha T, Tran C, Szaffarczyk S, Boucart M. The contribution of central and peripheral vision in scene categorization: A study on people with central vision loss. Vision Res. 2014;98:46-53. https://doi.org/10.1016/j.visres.2014. 03.004

29. Werth R, Scha G. Visual field loss in young children and mentally handicapped adolescents receiving Vigabatrin. Invest Ophthalmol Vis Sci. 2006;47(7):3028-3035. https://doi.org/10.1167/iovs.05-0778

30. Burge WK, Griffis JC, Nenert R, et al. Cortical thickness in human V1 associated with central vision loss. Sci Rep. 2016;6:23268. https://doi.org/10.1038/srep 23268

31. Tarita-Nistor L, González EG, Markowitz SN. Plasticity of fixation in patients with central vision loss. Vis Neurosci. 2009;26(5-6):487-494. https://doi.org/10.1017/ S0952523809990265

32. Hallemans A, Ortibus E, Meire F, Aerts P. Low vision affects dynamic stability of gait. Gait Posture. 2010;32(4):547-551. https://doi.org/10.1016/j.gaitpost.2010.07.018

33. Republic of Kenya: Final Draft: The national special needs education policy framework: Ministry of Education. 2009; p. 1-65.

34. Michailakis $D$, Reich W. Dilemmas of inclusive education Les dilemmes de l'éducation inclusive. Alter. 2009;3(1):24-44. https://doi.org/10.1016/j.alter.2008.10.001

35. Elder BC, Ed M. Right to inclusive education for students with disabilities in Kenya. J Int Spec Needs Educ. 2015;18(1):18-28. https://doi.org/10.9782/2159-4341 18.1.18

36. Janmohamed NS. Challenges facing implementation of inclusive education programme in public primary schools, Parklands district, Nairobi, Kenya [Dissertation]. Kenya: University of Nairobi. 2012
37. Wood JM. Vision and academic performance in primary school children. Ophthalmic Physiol Opt. 2018;38(5):516-524. https://doi.org/10.1111/opo.12582

38. Gilbert CE, Ellwein LB. Prevalence and causes of functional low vision in schoolage children: Results from standardized population surveys in Asia, Africa, and Latin America. Invest Ophthalmol Vis Sci. 2008;49(3):1-5. https://doi.org/ 10.1167/iovs.07-0973

39. Khan SA, Shamanna B, Nuthethi R. Perceived barriers to the provision of low vision services among ophthalmologists in India. Indian J Ophthalmol. 2005;53(1):69-75. https://doi.org/10.4103/0301-4738.15293

40. Dirani M, Zhang X, Goh LK, Young TL, Lee P. The role of vision in academic school performance. Ophthalmic Epidemiol. 2014;17(1):18-24. https://doi.org/10.3109/ 09286580903450320

41. Chung STL, Legge GE. Comparing the shape of contrast sensitivity functions for normal and low vision. Invest Ophthalmol Vis Sci. 2016;57:198-207. https://doi. org/10.1167/iovs.15-18084

42. Reynaud A, Gao Y, Hess RF. A normative dataset on human global stereopsis using the quick disparity sensitivity function (qDSF). Vision Res. 2015;113:97-103. https://doi.org/10.1016/j.visres.2015.04.021

43. Colenbrander A. Assessment of functional vision and its rehabilitation. Acta Ophthalmol. 2010;88(2):163-173. https://doi.org/10.1111/j.1755-3768.2009. 01670.x

44. Connor ARO, Birch EE, Anderson S, Draper $\mathrm{H}$. The functional significance of stereopsis. Invest Ophthalmol Vis Sci. 2016;57:198-207. https://iovs.arvojournals. org/article. aspx? articleid $=2484503$

45. Kotecha A, Chopra R, Fahy RTA, Rubin GS. Dual tasking and balance in those with central and peripheral vision loss. Investig Ophthalmol Vis Sci. 2013;54(8):54085415. https://doi.org/10.1167/iovs.12-12026

46. Dobson V, Quinn GE, Abromov I, et al. Color vision measured with pseudoisochromatic plates at five-and-a-half years in eyes of children from the CRYO-ROP study. Invest Ophthalmol Vis Sci. 1996;37(12):2467-2474.

47. Sugar O. Clinical neurosurgery. JAMA. 1975;232(3):75. https://doi.org/10.1001/ jama.1975.03250010055032

48. Werner JS, Keltner JL, Zawadzki RJ, Choi SS. Outer retinal abnormalities associated with inner retinal pathology in nonglaucomatous and glaucomatous optic neuropathies. Eye. 2011;25:279-289. https://doi.org/10.1038/eye.2010.218

49. Aprioku IN, Awoyesuku EA. Pattern and prevalence of color vision disorders amongst secondary school students in Rivers State, Nigeria. Ophthalmol Res. 2019;10(4):1-7. https://doi.org/10.9734/OR/2019/v10i430110 